\title{
Incidence of Placenta Accrete and its Complications in Cases of Previous Cesarean with Placenta Previa Anterior
}

\section{Gamal Mohamed Fouda ${ }^{1, *}$ MSc., Ismail Talet El Garhey ${ }^{1}$ MD., Ibrahim Hassan Mohamad ${ }^{1}$ MD.,} Adel Aly Elboghdady ${ }^{1}$ MD.

\author{
* Corresponding Author: \\ Gamal Mohamed Fouda \\ ahlylove888@gmail.com
}

Received for publication December 20, 2020; Accepted January 22, 2021; Published online January 22, 2021.

Copyright 2020 The Authors published by Al-Azhar University, Faculty of Medicine, Cairo, Egypt. All rights reserved. This an openaccess article distributed under the legal terms, where it is permissible to download and share the work provided it is properly cited. The work cannot be changed in any way or used commercially.

doi: $10.21608 /$ aimj.2021.54342.1378

${ }^{1}$ Obstetrics and Gynecology

Department, Faculty of Medicine, Al-Azhar University Cairo, Egypt.

\section{INTRODUCTION}

A preceding caesarean birth is the key risk factor for placenta accreta, especially when followed by a coexisting placenta previa. In order to improve maternal outcomes, antenatal diagnosis tends to be a major factor. In most instances, diagnosis may be done by ultrasound. ${ }^{1}$

It is unclear the precise pathogenesis of placenta accreta. A suggested theory involves a maldevelopment of decidua, excessive trophoblastic invasion, or a mixture of both. ${ }^{2}$

Clinically, when the placenta is not fully separated from the uterus accompanied by massive obstetric hemorrhage contributing to disseminated intravascular coagulation (DIC) and even deaths have been recorded, PA is problematic during childbirth, so the need for caesarean hysterectomy $(\mathrm{CH})$ in this case is a life-saving operation, but it has significant complications especially with bladder or parametrium invasion and irreversible loss of fertility with its psychological insult. For peripartum hysterectomy, PA accounts for $38 \% .^{3}$

Many obstetricians need and explain scheduled preterm birth to prevent bleeding or labour symptoms requiring emergent procedure. Cesarean delivery would be done in a tertiary care hospitals using a antenatally.

\section{ABSTRACT}

ackground: Placenta accreta is regarded to be a massive complication hemorrhage, which is severe and potentially life-threatening.

Aim of the work: Determination of the occurrence and complications of previa and outcome of management of these complications

Patients and methods: A prospective randomized analysis was at Al Hussein Hospital, Al-Azhar University from March 2020 Results: Prenatal diagnosis is important in optimizing the counseling, strongly correlated with placenta previa. The patient must be directed to a tertiary center when placenta accreta is diagnosed or suspected

Keywords: Placenta Accreta; Cesarean; Placenta Previa Anterior.

Disclosure: The authors have no financial interest to declare in the content of this article. The Article Processing Charge as paid for by the authors.

Authorship: All authors have a substantial contribution to the article.

disciplinary team management and possibility of ICU if needed.

The aim of this work to answer the question is there is a relation between the occurrence and complication of placenta accreta and the instances of placenta previa anterior?

\section{PATIENTS AND METHODS}

A prospective randomized study was performed on 100 cases of placenta previa centralis anterior with previous history of placenta previa centralis anterior and delivered by CS to show the incidence of placenta accreta in this pregnancy whom attended at Al Hussein Hospital, Al_Azhar University from March 2020 to November 2020.

Inclusion criteria: Between the ages of 18 and 35, Gestational age above 34 weeks, Parity: patient must have placenta previa anterior with at least one previous cesarean section and Singleton or multiple pregnancy.

Exclusion criteria: Patient with gestational age below 34 weeks, Patients with normally situated placenta, Patients with unscared uterus, or scared uterus rather than cesarean section and Patients with coagulopathy disease. 


\section{Ethical consideration:}

All of the participants have been volunteers. An informed written consent was signed by all of them and the purpose of the research prior the start of the research was clarified. Approval was received from the ethical committee at Al-Azhar University, Faculty of Medicine.

\section{Statistical analysis:}

The reported data was analysed using version 20.0 of the statistical package for social sciences (SPSS Inc., Chicago, Illinois, USA). The mean \pm standard deviation (SD) was represented as quantitative data. The frequency and percentage were represented as qualitative data.

The following tests were done: When comparing two means, independent-samples t-test of significance has been used. The Chi-square (x2) significance test has been used to compare the proportions of qualitative parameters. Diagnostic performance assessment: Sensitivity $=($ true $+v e) /[($ true $+v e)+($ false $-v e)]$, Specificity $=($ true $-v e) /[($ true $-v e)+($ false $+v e)]$, $\mathrm{PPV}=($ true $+\mathrm{ve}) /[($ true $+\mathrm{ve})+($ false $+\mathrm{ve})], \mathrm{NPV}=$ $($ true $-\mathrm{ve}) /[($ true $-\mathrm{ve})+($ false $-\mathrm{ve})]$ and Accuracy $=$ $(\mathrm{TP}+\mathrm{TN}) /[\mathrm{TP}+\mathrm{FP}+\mathrm{TN}+\mathrm{FN}]$

The confidence interval has been set at $95 \%$ and the agreed error margin has been set at 5\%. Therefore the p-value has been deemed significant as the following: Probability (P-value): P-value $<0.05$ has been deemed significant, $\mathrm{P}$-value $<0.001$ has been deemed as highly significant and P-value $>0.05$ has been deemed insignificant.

\section{RESULTS}

\begin{tabular}{|c|c|c|c|c|c|}
\hline $\begin{array}{l}\text { Demograp } \\
\text { hic data }\end{array}$ & $\begin{array}{l}\text { Accreta } \\
\text { group } \\
(n=61)\end{array}$ & $\begin{array}{c}\text { Not } \\
\text { Accreta } \\
\text { group } \\
(\mathbf{n}=39)\end{array}$ & $\begin{array}{c}\text { Total } \\
(\mathbf{n}=\mathbf{1 0 0})\end{array}$ & $\begin{array}{c}\text { Tes } \\
\text { t }\end{array}$ & $\begin{array}{c}\text { p- } \\
\text { value }\end{array}$ \\
\hline $\begin{array}{c}\text { Age } \\
\text { (years) }\end{array}$ & $\begin{array}{c}33.58 \pm 5 \\
17\end{array}$ & $\begin{array}{c}30.01 \pm 5 \\
04\end{array}$ & $\begin{array}{c}31.80 \pm 5 \\
10\end{array}$ & $\begin{array}{c}3.40 \\
1\end{array}$ & $\begin{array}{c}<0.00 \\
1^{* *}\end{array}$ \\
\hline $\begin{array}{l}\text { Gestation } \\
\text { al age } \\
\text { (wks) }\end{array}$ & $\begin{array}{c}36.98 \pm 4 \\
68\end{array}$ & $\begin{array}{c}36.05 \pm 2 \\
90\end{array}$ & $\begin{array}{c}36.51 \pm 3 \\
79\end{array}$ & $\begin{array}{c}1.11 \\
1\end{array}$ & 0.269 \\
\hline
\end{tabular}

t-Independent Sample t-test

p-value $>0.05 \quad \mathrm{NS} ; \quad *$ p-value $<0.05 \quad \mathrm{~S} ; \quad * *$ p-value $<0.001 \mathrm{HS}$

Table 1: Comparison of the Accreta group with the non-Accreta group based on demographic data.

This table displays statistically significant increase average in Accreta group relative to Not Accreta group as per age, while gestational age insignificant.

\begin{tabular}{|c|c|c|c|c|c|}
\hline $\begin{array}{c}\text { Antepartum } \\
\text { haemorrhge }\end{array}$ & $\begin{array}{c}\text { Accreta } \\
\text { group } \\
(\mathbf{n = 6 1})\end{array}$ & $\begin{array}{c}\text { Not } \\
\text { Accreta } \\
\text { group } \\
(\mathbf{n = 3 9})\end{array}$ & $\begin{array}{c}\text { Total } \\
(\mathbf{n = 1 0 0})\end{array}$ & $\mathbf{x}^{\mathbf{2}}$ & $\begin{array}{c}\mathbf{p}- \\
\text { value }\end{array}$ \\
\hline Positive & $\begin{array}{c}41 \\
(67.2 \%)\end{array}$ & $33(84.6 \%)$ & $\begin{array}{c}74 \\
(74.0 \%)\end{array}$ & \multirow{2}{*}{2.892} & 0.089 \\
\cline { 1 - 4 } Negative & $\begin{array}{c}20 \\
(32.8 \%)\end{array}$ & $6(15.4 \%)$ & $\begin{array}{c}26 \\
(26.0 \%)\end{array}$ & & \\
\hline
\end{tabular}

$\mathrm{x}^{2}$ : Chi-square test; $\mathrm{p}$-value $>0.05 \mathrm{NS}$

Table 2: Comparison of the Accreta group with the non-Accreta group based on antepartum haemorrhge (AP hg)

This Table displays that there is no significant relation among the AP hg and definitive diagnosis of placenta accreta as This Table shows that 74 cases have AP hg 41 of them proved to be accreta, while 33 cases were not Accreta, while 26 cases have no AP hg 20 of them proved to be Accreta and 6 cases of them proved to be not accreta by pathological examination.

\begin{tabular}{|c|c|c|c|c|c|}
\hline $\begin{array}{c}\text { Site of } \\
\text { placenta }\end{array}$ & $\begin{array}{c}\text { Accreta } \\
\text { group } \\
(n=61)\end{array}$ & $\begin{array}{c}\text { Not } \\
\text { Accreta } \\
\text { group } \\
(\mathbf{n}=39)\end{array}$ & $\begin{array}{c}\text { Total } \\
(\mathbf{n}=\mathbf{1 0 0})\end{array}$ & $x^{2}$ & $\begin{array}{c}\text { p- } \\
\text { value }\end{array}$ \\
\hline Marginalis & $\begin{array}{c}10 \\
(16.4 \%)\end{array}$ & $\begin{array}{c}18 \\
(46.2 \%)\end{array}$ & $\begin{array}{c}28 \\
(28.0 \%)\end{array}$ & \multirow{3}{*}{11.801} & \multirow{3}{*}{$0.003^{*}$} \\
\hline $\begin{array}{l}\text { Incomplete } \\
\text { centralis }\end{array}$ & $\begin{array}{c}10 \\
(16.4 \%)\end{array}$ & $\begin{array}{c}7 \\
(17.9 \%)\end{array}$ & $\begin{array}{c}17 \\
(17.0 \%)\end{array}$ & & \\
\hline $\begin{array}{c}\text { Complete } \\
\text { centralis }\end{array}$ & $\begin{array}{c}41 \\
(67.2 \%)\end{array}$ & $\begin{array}{c}14 \\
(35.9 \%)\end{array}$ & $\begin{array}{c}55 \\
(55.0 \%)\end{array}$ & & \\
\hline
\end{tabular}

$\mathrm{x}^{2}$ : Chi-square test; *p-value $<0.05 \mathrm{~S}$

Table 3: Comparison of the Accreta group with the non-Accreta group based on site of placenta

This Table displays that the total incidence of placenta accreta is $61 \%$ and there is significant relation between the site of placenta and definitive diagnosis of placenta accreta by pathological examination.

\begin{tabular}{|c|c|c|}
\hline Results & No. & \% \\
\hline Accreta & 31 & $50.8 \%$ \\
\hline Increta & 21 & $34.4 \%$ \\
\hline Percreta & 9 & $14.8 \%$ \\
\hline
\end{tabular}

Table 4: Distribution of histopathological results in 61 patients who have patholopgical placentation and performed cesarean hysterectomy.

This Table displays that 31 cases $(50.8 \%)$ accreta (true $+v e), 21$ cases $(34.4 \%)$ increta (true +ve cases), 9 cases $(14.8 \%)$ percreta (true $+v e$ ), It was noted that placenta accreta was the most common pathology than placenta increta and percreta, represented $50.8 \%, 34.4 \%$, and $14.8 \%$ respectively. 


\begin{tabular}{|c|c|c|c|c|c|}
\hline $\begin{array}{c}\text { No. } \\
\text { of } \\
\text { P.C.S }\end{array}$ & $\begin{array}{c}\text { Accreta } \\
\text { group } \\
(\mathrm{n}=61)\end{array}$ & $\begin{array}{c}\text { Not } \\
\text { Accreta } \\
\text { group } \\
(\mathrm{n}=39)\end{array}$ & $\begin{array}{c}\text { Total } \\
(\mathbf{n}=100)\end{array}$ & $x^{2}$ & p-value \\
\hline 1 & $3(4.9 \%)$ & $\begin{array}{c}19 \\
(48.7 \%)\end{array}$ & $\begin{array}{c}22 \\
(22.0 \%)\end{array}$ & \multirow{5}{*}{32.028} & \multirow{5}{*}{$<0.001 * *$} \\
\hline 2 & $\begin{array}{c}15 \\
(24.6 \%)\end{array}$ & $\begin{array}{c}11 \\
(28.2 \%)\end{array}$ & $\begin{array}{c}26 \\
(26.0 \%)\end{array}$ & & \\
\hline 3 & $\begin{array}{c}25 \\
(41.0 \%)\end{array}$ & $\begin{array}{c}7 \\
(17.9 \%)\end{array}$ & $\begin{array}{c}32 \\
(32.0 \%)\end{array}$ & & \\
\hline 4 & $\begin{array}{c}15 \\
(24.6 \%)\end{array}$ & $2(5.1 \%)$ & $\begin{array}{c}17 \\
(17.0 \%)\end{array}$ & & \\
\hline 5 & $3(4.9 \%)$ & $0(0.0 \%)$ & $\begin{array}{c}3 \\
(3.0 \%)\end{array}$ & & \\
\hline
\end{tabular}

$\mathrm{x}^{2}$ : Chi-square test; **p-value $<0.001 \mathrm{HS}$

Table 5: Relation between the number of previous cesarean section (P.C.S) and the definitive diagnosis of normal and abnormal placenta in all cases

This Table displays that there is high significant relationship among number of previous cesarean section (P.C.S) and the definitive diagnosis of normal and abnormal placenta in all studied cases ( $p$-value $<0.001)$

\begin{tabular}{|c|c|c|c|c|c|}
\hline $\begin{array}{c}\text { ICU } \\
\text { admissi } \\
\text { on }\end{array}$ & $\begin{array}{c}\text { Accreta } \\
\text { group } \\
(\mathbf{n = 6 1 )}\end{array}$ & $\begin{array}{c}\text { Not } \\
\text { Accreta } \\
\text { group } \\
(\mathbf{n = 3 9})\end{array}$ & $\begin{array}{c}\text { Total } \\
(\mathbf{n = 1 0 0})\end{array}$ & \multirow{2}{*}{$\boldsymbol{x}^{2}$} & p-value \\
\hline Positive & $\begin{array}{c}39 \\
(63.9 \%)\end{array}$ & $2(5.1 \%)$ & $\begin{array}{c}41 \\
(41.0 \%)\end{array}$ & \multirow{2}{*}{31.62} & $<0.001^{* *}$ \\
\cline { 1 - 4 } Negative & $\begin{array}{c}22 \\
(36.1 \%)\end{array}$ & $\begin{array}{c}37 \\
(94.9 \%)\end{array}$ & $\begin{array}{c}59 \\
(59.0 \%)\end{array}$ & & \\
\hline
\end{tabular}

x2: Chi-square test; $* *$ p-value $<0.001 \mathrm{HS}$

Table 6: Relation between intensive care unit (ICU) admission and the definitive diagnosis of normal and abnormal placenta in all studied cases

This Table displays that there is high significant relationship among ICU admission and the definitive diagnosis of normal and abnormal placenta ( $\mathrm{P}$-value $<0.001) 41$ cases $(41 \%)$ admitted in ICU, 39 cases (63.9\%) of them were placenta accreta, and 2 cases (5.1\%) have normal placenta. While 59 cases $(59 \%)$ not admitted in ICU, 22 cases $(36.1 \%)$ of them were placenta accreta, and 37 cases $(94.9 \%)$ have normal placenta.

\begin{tabular}{|c|c|c|c|c|c|}
\hline $\begin{array}{c}\text { Neonata } \\
\text { l Apgar } \\
\text { score }\end{array}$ & $\begin{array}{c}\text { Accreta } \\
\text { group } \\
(\mathbf{n}=\mathbf{6 1})\end{array}$ & $\begin{array}{c}\text { Not } \\
\text { Accreta } \\
\text { group } \\
(\mathbf{n}=\mathbf{3 9})\end{array}$ & $\begin{array}{c}\text { Total } \\
(\mathbf{n}=\mathbf{1 0 0})\end{array}$ & $\begin{array}{c}\mathbf{t}- \\
\text { test }\end{array}$ & $\begin{array}{c}\mathbf{p}- \\
\text { valu } \\
\mathbf{e}\end{array}$ \\
\hline $\begin{array}{c}\text { Mean } \pm \mathbf{S} \\
\text { D }\end{array}$ & $\begin{array}{c}7.26 \pm 1 . \\
00\end{array}$ & $\begin{array}{c}6.85 \pm 1 . \\
31\end{array}$ & $\begin{array}{c}4.29 \pm 0 . \\
49\end{array}$ & $\begin{array}{c}1.30 \\
6\end{array}$ & $\begin{array}{c}0.21 \\
7\end{array}$ \\
\hline
\end{tabular}

t: Independent Sample t-test; p-value >0.05 NS

Table 7: Comparison between Accreta group and Not Accreta group according to Apgar score

This Table displays that there are no significant relation among neonatal APGER score and definitive diagnosis of normal and abnormal placenta in all cases, as $p$ value 0.217 .

\section{DISCUSSION}

Placenta accreta is regarded to be a massive complication in pregnancy that can be correlated with intrapartum and postpartum hemorrhage, which is severe and potentially life-threatening. ${ }^{5}$

Placenta accreta is ideally diagnosed by sonographic or magnetic resonance imaging techniques in the antenatal period. Several researches especially at more than 20 weeks of gestation have shown the utility of ultrasonography in making this diagnosis. Sadly, when the mother encounters continued vaginal bleeding or severe vaginal bleeding, some instances of placenta accreta are diagnosed at the time of delivery. ${ }^{6}$

This work was aimed at determining the occurrence and complications of placenta accreta in instances of prior cesarean sections with placenta previa and outcome of management of these complications.

This study showed that the mean increase in the placenta accreta group was statistically significant relative to the non-accreta group by age, while gestational age showed insignificant difference.

A study showed that the demographic data as age and previous number of cesarean section of women included in his study were inversely related to the presence of Accreta which supports this results. ?

Also, two studies concluded that patients with PA was conducted to more young age (30.45) due to increasing rates of cesarean delivery $(56.52 \%){ }^{8,9}$

This study revealed that there was no significant relation between the Antepartum hemorrhage (AP $\mathrm{hg}$ ) and the definitive diagnosis of placenta accreta as 74 cases have AP hg , 41 of them proved to be accreta, while 33 cases were not Accreta, while 26 cases have no AP hg 20 of them proved to be Accreta and 6 cases of them proved to be not accreta by pathological examination and these results counteract those of a systematic review which concluded that the incidence of APH between females with placenta previa was $51.9 \%$, varying from $20 \%$ to $78 \%$. ${ }^{10}$

A study also revealed no significant relation between the Antepartum hemorrhage (AP hg) and the definitive diagnosis of placenta Accreta which also matching this results. ${ }^{11}$

Regarding the incidence of placenta Accreta in this study which was $61 \%$ and there was significant relation between the site of placenta and definitive diagnosis of placenta accreta by pathological examination and this nearly matched the study which found that the incidence of placenta accreta with placenta previa anterior was $63 \%$ in instances of prior caesarean section and this marked rise in the occurrence was due to the growing prevalence of caesarean delivery in recent times. ${ }^{12}$

Two studies also showed that in instances of placenta previa correlated with abnormal placentation, postpartum ICU entry, extended hospital staying and CS hysterectomy became more popular. ${ }^{13,14}$

Regarding the histopathological results of the patients who have patholopgical placentation and 
performed cesarean hysterectomy, this study showed that 31 cases $(50.8 \%)$ accreta (true +ve), 21 cases (34.4\%) increta (true +ve cases), 9 cases $(14.8 \%)$ percreta (true $+v e)$, It was noted that placenta accreta was the most common pathology than placenta increta and percreta, represented $50.8 \%, 34.4 \%$, and $14.8 \%$ respectively.

It was noted in this study that placenta accreta was the most common pathology than placenta increta and percreta, represented $50.8 \%, 34.4 \%$, and $14.8 \%$ respectively in agreement with a study which reported that placenta accreta was much more common than placenta increta and percreta. ${ }^{12}$

This study showed highly significant relation between the number of previous cesarean section (P.C.S) and the definitive diagnosis of normal and abnormal placenta in all studied cases ( $p$-value $<0.001)$.

A study showed significant relation between abnormal placenta (accreta, increta or percreta) and number of previous cesarean sections, as whenever the number of previous cesarean section (P.C.S) increased the frequency of abnormal placenta also increased, $14.2 \%$ with one previous cesarean section, $60 \%$ with two previous cesarean section, $79.4 \%$ with three previous cesarean section, $88.23 \%$ with four previous cesarean section, and 3 cases with five previous cesarean section all of them were accreta. ${ }^{12}$

A study demonstrated the relation between the placenta accreta in women with placenta praevia and the number of caesarean births, also reported that in women with placenta praevia, the incidence of placenta acreta rises with an growing number of caesarean births as following: in women with placenta praevia and no previous cesarean birth 1 to $5 \%$, with one previous cesarean birth 11 to $25 \%$, with two previous cesarean birth 35 to $47 \%$, with three prior cesarean deliveries $40 \%$, and with four or more prior cesarean deliveries 50 to $67 \% .^{15}$

In this study, we found significant relation between bladder injury complication and the definitive diagnosis of normal and abnormal placenta (P-value less than $<0.001)$ in accordance with a study which found that the bladder was injured and repaired in 19 of 40 cases $(47.5 \%)$ all of them with abnormal placenta, while no bladder injury in cases of normal placenta. ${ }^{12}$

Regarding the APGER score, there has been no significant relationship among neonatal APGER score and definitive diagnosis of normal and abnormal placenta in all cases, as p value 0.217 in agreement with a study which also revealed no significant difference between the APGER score and definitive diagnosis of normal and abnormal placenta. ${ }^{12}$

\section{CONCLUSION}

Placenta accreta, particularly in cases with previous CS, is strongly correlated with placenta previa. The patient must be directed to a tertiary center when placenta accreta is diagnosed or suspected antenatally.

\section{REFERENCES}

1. Timor-Tritsch IE, D'Antonio F, Cal' G,et al. A. Early first-trimester transvaginal ultrasound is indicated in pregnancy afterprevious Cesarean delivery: should it bemandatory?. Ultrasound Obstet Gynecol., 2019; 54: 156-63.

2. Shawky M, AbouBieh E and Masood A. Gray scale and Doppler ultrasound in placenta accreta: Optimization of ultrasound signs. The Egyptian Journal of Radiology and Nuclear Medicine, 2016; 47(3): 1111-5.

3. Khan L, Rahim A and Gardezi J. Conventional and conservative management of placenta accreta is two ends of a single continuum: A report of three cases and literature review. Clin Case Rep. 2018; 6(9): 1739-46.

4. Silver RM, Fox KA, Barton JR, et al. Center of excellence for placenta accreta. $A m J$ ObstetGynecol 2015; 212: 561-8.

5. Ibrahim TH. Efficacy of tranexamic acid in reducing blood loss, blood and blood products requirements in Cesarian sections for patients with placenta accreta. Ain-Shams $J$ Anesthesiol., 2019; 11(31).

6. Satija B, Kumar S, Wadhwa L, et al. Utility of ultrasound and magnetic resonance imaging in prenatal diagnosis of placenta accreta: A prospective study. The Indian journal of radiology \& imaging. 2015; 25(4): 464-70.

7. Fahmy M, Alhalabi A, Hamza H, et al. Role of uterine artery Doppler in the diagnosis of placenta Accreta in patients with placenta previa. Menoufia Med J 2020; 33: 497-500

8. Kansouh AM and Serag Eldin EM. Maternal outcomes after different surgical techniques in placenta accreta: a prospective study. J Med Sci Res 2018; 1: 306-11

9. Garmi G and Salim R. Epidemiology, etiology, diagnosis, and management of placenta accreta. Obstet Gynecol Int 2012; Article ID 87392.

10. Fan D, Wu S and Liu L. Prevalence of antepartum hemorrhage in women with placenta previa: a systematic review and metaanalysis. Sci Rep. 2017; 7: 40320.

11. El Lakwa H, Sanad Z, Hamza HA, et al. Evaluation of placenta accreta index to predict placental invasion in patients with placenta previa. Menoufia Med J 2019; 32: 1359-64.

12. Al Senitty AME, Mohamed AH and Ahmed IM. Incidence of Placenta Accreta and its Complications in Cases of Previous Cesearean Sections with Placenta Previa Anterior at $\mathrm{Al}$ Hussein University Hospital. The Egyptian Journal of Hospital Medicine, 2018; 73(3): 63105 
13. Algebally AM, Yousef RR, Badr SS, et al. The value of ultrasound and magnetic resonance imaging in diagnostics and prediction of morbidity in cases of placenta previa with abnormal placentation. Polish journal of radiology. 2014; 79: 409.
14. Eller G, Porter TT, Soisson P, et al. Optimal management strategies for placenta, $A n$ International Journal of Obstetrics and Gynaecology, 2009; 116(5): 648-54.

15. Silver RM, Landon MB, Rouse DJ, et al. Maternal morbidity associated with multiple repeat cesarean deliveries. Obstetrics and Gynecology, 2006; 107 (6): 1226-32. 